\title{
Systemic Necrotizing Vasculitis with Renal Involvement Accompanied by Remarkable Eosinophilia: A Case with Overlapping Features of Polyarteritis Nodosa and Allergic Granulomatous Angiitis
}

\author{
Toshiyuki SASAguri, Masasuke SoEJIMA*, Yoshiyuki HiNO*, Hirokazu SHIRAISHI, \\ Hirokazu DATE, Masayuki TAKASUGI*, Akihide TANIMOTO** and Akio HoRIE***
}

\begin{abstract}
A 71-year-old woman was clinically suspected of allergic granulomatous angiitis (AGA) because of preceding allergic diseases including bronchial asthma, remarkable eosinophilia $\left(14,300 / \mathrm{mm}^{3}\right)$, mononeuritis multiplex, positive rheumatoid factor, elevated serum immunoglobulin $E$, and eosinophilic inflammation of the kidney. Autopsy findings, however, were characteristic of polyarteritis nodosa (PAN). Necrotizing angiitis was present in several organs except for the lung; focal and segmental glomerular lesions with crescent formation were observed in the kidney, and granuloma formation was not found. This case may be an intermediate type between PAN and AGA (an overlap syndrome) and provide useful information on the clinical entities of systemic necrotizing vasculitis.
\end{abstract}

Key words: Polyangiitis overlap syndrome, Kidney biopsy

The clinical spectrum of systemic necrotizing vasculitis has been expanding since classical polyarteritis nodosa (PAN), the prototype of vasculitic syndromes, was first described by Kussmaul and Maier in 1866 (1). In 1951, Churg and Strauss proposed allergic granulomatous angiitis (AGA) as a clinical entity distinct from PAN (2). AGA is characterized by multisystemic vasculitis accompanied by hypereosinophilia occurring in individuals with allergic disorders such as bronchial asthma, urticaria and allergic rhinitis (3-5). It is not always easy, however, to distinguish AGA from PAN clinically. In fact, several patients have been reported to manifest systemic vasculitis but have no features that put the disorder definitively into a single category or whose manifestations overlap several of the well-defined and distinct syndromes, e.g. PAN or AGA $(6,7)$.

We report herein an uncommon case of systemic necrotizing vasculitis, which was clinically suspected of AGA but was found to have several histological features of classical PAN on the postmortem examination.

\section{REPORT OF A CASE}

A 71-year-old woman was admitted to Ashiya Municipal Hospital on August 3, 1989, because of high fever and inability of dorsi-flexion of the left ankle.

The patient often suffered from allergic reactions including seafood urticaria, allergic rhinitis and bronchial asthma, but was otherwise healthy until about 1 yr before admission. From that time she was often febrile and lost weight. One month earlier high

From Ashiya Municipal Hospital, Fukuoka, *The Second Department of Internal Medicine, **Department of Pathology and Toxicologic Pathology, ***Department of Pathology and Oncology, University of Occupational and Environmental Health, Japan, School of Medicine, Kitakyusyu

Received for publication July 30, 1990; Accepted for publication February 1, 1991

Reprint requests should be addressed to Toshiyuki Sasaguri, MD, National Cardiovascular Center, Research Institute, 5-7-1 Fujishiro-dai, Suita 565, Japan 
fever appeared and continued. Five days before entry she felt burning pain on the dorsal surface of her left ankle, and she became unable to lift up her left foot on the next day. Asthmatic symptoms had appeared for the first time $9 \mathrm{yr}$ prior to the admission, but had been absent for 1 yr prior to admission. She had a history of rectal cancer resection $15 \mathrm{yr}$ earlier. She had not taken any drugs and there was no family history of allergic disorders or collagen diseases.

On examination the patient was emaciated (ht $142.5 \mathrm{~cm}$, wt $32.0 \mathrm{~kg}$ ), but was alert and oriented. The temperature was $38.2^{\circ} \mathrm{C}$ and remittent, the pulse was 70 and irregular, and the respirations were 18 . The blood pressure was $150 / 88 \mathrm{mmHg}$. Although no cutaneous lesion was found, small, soft and painless superficial lymphnodes were palpable in her cervical, supraclavicular, axillar and inguinal regions. Optic fundi were normal. No rales were audible in her chest. There was an artificial anal orifice on the left anterior wall of her abdomen. She was unable to perform dorsi-flexion of the left ankle and toe joints. The ankle jerk was absent bilaterally.

Results of the laboratory examination are shown in Table 1. The urine test was positive for protein; the sediment contained numerous erythrocytes, hyaline casts and granular casts. Remarkable eosinophilia was observed in the peripheral blood. Bone marrow picture showed hyperplasia of eosinophils without malignant cells. Erythrocyte

Table 1. Laboratory tests.

\begin{tabular}{|c|c|c|c|}
\hline Urine test & & $\mathrm{LDH}$ & $679 \mathrm{IU} / 1$ \\
\hline protein & $(+)$ & $\mathrm{CK}$ & $49 \mathrm{IU} / 1$ \\
\hline erythrocytes & many & BUN & $12.4 \mathrm{mg} / \mathrm{dl}$ \\
\hline leukocytes & $1-5 / \mathrm{HPF}$ & Creatinine & $0.9 \mathrm{mg} / \mathrm{dl}$ \\
\hline hyaline casts & many & Uric acid & $2.9 \mathrm{mg} / \mathrm{dl}$ \\
\hline granular casts & $11 / \mathrm{HPF}$ & Serological tests & \\
\hline Stool test & & CRP & $(+++++)$ \\
\hline occult blood & $(+)$ & $\mathrm{C} 3$ & $82 \mathrm{mg} / \mathrm{dl}$ \\
\hline parasite ova & $(-)$ & $\mathrm{C} 4$ & $31 \mathrm{mg} / \mathrm{dl}$ \\
\hline Erythrocyte sedimentation rate & & $\mathrm{CH} 50$ & $34.6 \mathrm{U} / \mathrm{ml}$ \\
\hline $19 \mathrm{~mm} / \mathrm{h}, 54 \mathrm{~mm} / 2 \mathrm{~h}$ & & IgG & $2,200 \mathrm{mg} / \mathrm{dl}$ \\
\hline Blood cell count & & $\operatorname{Ig} \mathrm{A}$ & $153 \mathrm{mg} / \mathrm{dl}$ \\
\hline erythrocytes & $303 \times 10^{4} / \mathrm{mm}$ & $\operatorname{IgM}$ & $134 \mathrm{mg} / \mathrm{dl}$ \\
\hline hemoglobin & $8.7 \mathrm{~g} / \mathrm{dl}$ & IgE (RIST) & $360 \mathrm{IU} / \mathrm{ml}$ \\
\hline hematocrit & $26.6 \%$ & cryoglobulin & $(-)$ \\
\hline leukocytes & $19,300 / \mathrm{mm}^{3}$ & HBs $\mathrm{Ag}$ & $(-)$ \\
\hline basophils & $1 \%$ & RA test & $(+)$ \\
\hline eosinophils & $74 \%$ & RAHA test & $<\times 40$ \\
\hline stab & $2 \%$ & LE test & $(-)$ \\
\hline segment & $17 \%$ & antinuclear $\mathrm{Ab}$ & $(-)$ \\
\hline lymphocytes & $5 \%$ & anti-DNA $\mathrm{Ab}$ & $2.5 \mathrm{IU} / \mathrm{ml}$ \\
\hline monocytes & $1 \%$ & thyroid test & $<\times 100$ \\
\hline platelets & $260,000 / \mathrm{mm}^{3}$ & microsome test & $<\times 100$ \\
\hline Bone marrow analysis & & Endocrinological examination & \\
\hline nuclear cells & $278,500 / \mathrm{mm}^{3}$ & $\mathrm{ACTH}$ & $16.5 \mathrm{pg} / \mathrm{ml}$ \\
\hline $\mathrm{M}: \mathrm{E}$ & $8.9: 1$ & cortisol & $20.9 \mu \mathrm{g} / \mathrm{dl}$ \\
\hline eosinophils & $40.4 \%$ & Renal function tests & \\
\hline Serum chemistry & & $\mathrm{Ccr}$ & $41.0 \mathrm{ml} / \mathrm{min}$ \\
\hline Total protein & $5.5 \mathrm{~g} / \mathrm{dl}$ & PSP test & $51 \% / 2 \mathrm{~h}$ \\
\hline albumin & $47.6 \%$ & U- $\beta_{2}$ microglob. & $660 \mu \mathrm{g} /$ day \\
\hline$\alpha_{1}$-glob. & $8.3 \%$ & $\mathrm{U}-\alpha_{1}$ microglob. & $38.3 \mathrm{mg} /$ day \\
\hline$\alpha_{2}$-glob. & $11.5 \%$ & U-NAG & $33.1 \mathrm{U} / 1$ \\
\hline$\beta$-glob. & $8.2 \%$ & & \\
\hline$\gamma$-glob. & $24.4 \%$ & & \\
\hline
\end{tabular}


sedimentation rate was accelerated, $\alpha_{2}$-globulin was increased, and $\mathrm{C}$-reactive protein was strongly positive. Hypoalbuminemia was present with a relative increase in $\gamma$-globulin, and lactate dehydrogenase activity was elevated. Rheumatoid factor was positive on the RA test, though RAHA titre was not elevated. Increases were observed in the serum immunoglobulin $G$ and $E$ levels although not remarkable. Parasite ovum was not detected in the stool examination in spite of positive occult blood. Impairment of renal function was revealed by some tests.

No abnormality was found in the chest X-ray film except for increased cardiothoracic ratio $(62.3 \%)$. Electrocardiogram suggested inferior and lateral wall ischemia (Fig. 1). A small amount of

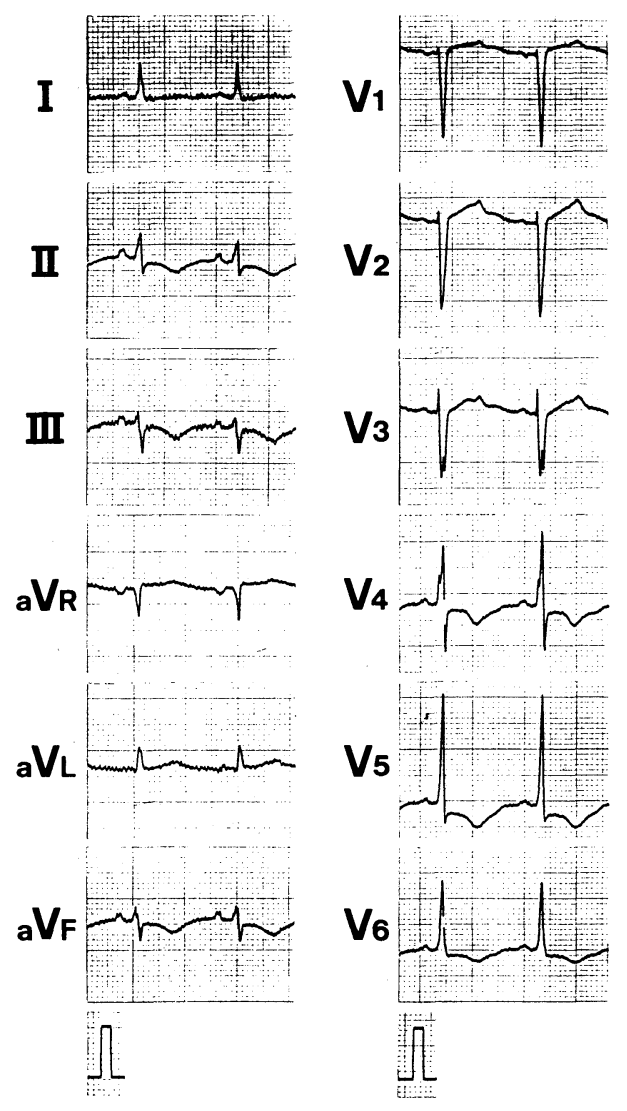

Fig. 1. Electrocardiogram. Sinus rate was $79 / \mathrm{min}$. QRS axis was -4 degrees. Downward ST segment depression and inverted $\mathrm{T}$ wave were observed in leads II, III, $\mathrm{aV}_{\mathrm{F}}, \mathrm{V}_{4}, \mathrm{~V}_{5}$ and $\mathrm{V}_{6}$. Ventricular premature contractions were present sporadically, although not shown. pericardial effusion was detected on the echocardiogram. Bilateral solitary cysts of the kidney were found on the echorenogram (not shown).

Five days after admission weakness appeared in her right ankle, left knee and left arm as well. Upon the measurement of nerve conduction velocity, a delay was observed in the left peroneal nerve. Biopsy specimen of the left sural nerve and anterior tibial muscle showed mild non-specific inflammation. Muscle weakness was worsened day by day and spread to all the extremities. She also complained of numbness and hyperalgesia of the legs. Petechiae appeared transiently on her palpebral conjunctiva and oral mucosa. Two weeks after admission a small amount of pleural effusion was observed bilaterally.

Renal biopsy was performed on August 23. Histological examination revealed perivascular infiltration of eosinophils, intimal thickening of small arteries, and tubular atrophy and degeneration with hyaline or red cell casts. However, glomeruli were nearly intact, and there was no fibrinoid necrosis or granuloma formation in the arterial walls.

In the early morning on August 24, her abdomen was tense, blood pressure dropped, and hemoglobin fell to $3.5 \mathrm{~g} / \mathrm{dl}$. Echogram revealed a huge retroperitoneal hematoma around the right kidney expanding beyond the median line. In spite of emergency blood transfusion, the patient lost consciousness in the evening and soon her respiration ceased. Although cardiopulmonary resuscitation with a mechanical ventilator was performed, she remained unconscious. She was transferred to the intensive care unit of the School of Medicine of the University of Occupational and Environmental Health of Japan, on August 26. She died, however, after ventricular arrhythmia suddenly occurred on August 29.

The postmortem examination revealed systemic necrotizing vasculitis involving heart, kidney, liver, gall bladder, spleen, esophagus, stomach, jejunum, ileum, uterus, and adrenal capsule. Affected vessels were medium- to small-sized muscular arteries (about $500 \mu \mathrm{m}$ in diameter). Large conduit arteries including main branches of the coronary arteries and the renal arteries were nearly intact and venous involvement was not detected. Vasculitis was not found in the lung, although the basal lamina and smooth muscle of the bronchial mucosa were 
thickened due to bronchial asthma. In the kidney, fibrinoid necrosis associated with an inflammatory infiltrate was observed through all the layers of arteries and elastic membranes were disrupted (Fig. 2). Glomeruli were also severely affected manifesting focal and segmental necrotizing glomerulitis with focal crescent formation (Figs. 2, 3). There were some foci of old and fresh subendocardial infarction in the myocardium. Other findings were considered to be secondary to massive bleeding. These include retroperitoneal hematoma around the right kidney, approximately $15 \times 20 \mathrm{~cm}$, anoxic change of the brain, and disseminated fibrin thrombi in multiple organs. Macroscopically there was no evidence of such an injury to the blood vessels that could have caused massive bleeding, although a small coagulum probably formed by the biopsy was observed in the right kidney.

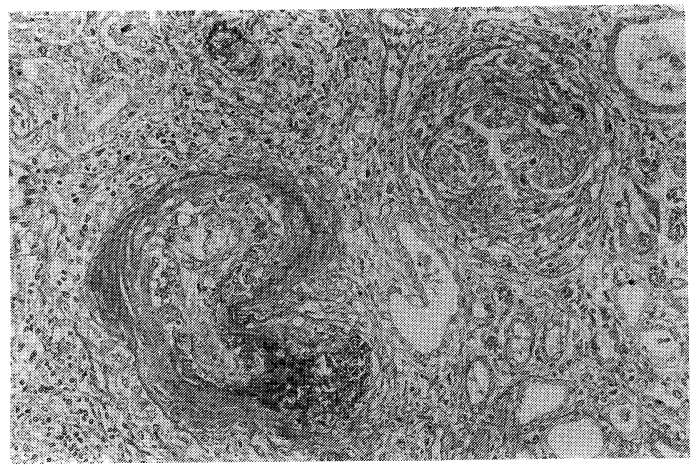

Fig. 2. Acute necrotizing vasculitis of a medium-sized artery. The endothelium is denuded and intimal fibrin deposits have narrowed the lumen. There is a marked cellular crescent in the adjacent glomerulus (PAS $\times 40$ ).

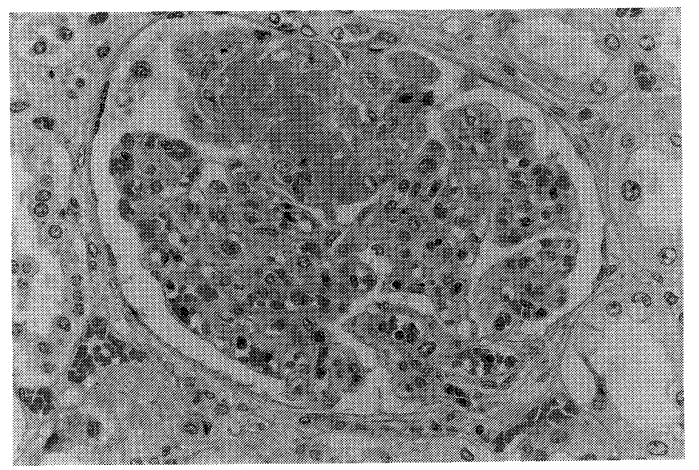

Fig. 3. Glomerulus exhibiting segmental necrosis of the tuft with fibrinoid deposition $(\mathrm{HE} \times 200)$.

\section{DISCUSSION}

Today it seems to be generally accepted that AGA is a distinguishable clinical entity from other types of vasculitis $(4,5)$. The features of AGA described by Churg and Strauss consist of clinical manifestations including bronchial asthma, fever, hypereosinophilia and vasculitic syndrome, and histological findings including necrotizing vasculitis, granulomatous angiitis and extravascular granuloma (2). The present case was initially suspected to be AGA, because the patient had several of the above clinical features, although the biopsies could not detect characteristic lesions.

In 1988, Nagasawa made diagnostic criteria of AGA based on 74 cases diagnosed as AGA using a guideline proposed by himself previously $(8,9)$. According to his criteria, definitive diagnosis of AGA is made if a patient manifests a vasculitis syndrome preceded by bronchial asthma and eosinophilia, and one of the following laboratory findings is present; leukocytosis (more than $10,000 / \mathrm{mm}^{3}$ ), thrombocytosis (more than $400,000 / \mathrm{mm}^{3}$ ), accelerated erythrocyte sedimentation rate (more than 60 $\mathrm{mm} / \mathrm{h}$ ), increased serum immunoglobulin $\mathrm{E}$ (more than $600 \mathrm{IU} / \mathrm{ml}$ ) or positive rheumatoid factor. The present case well meets these criteria; the patient had a history of asthma, eosinophils were remarkably increased, mononeuritis multiplex and renal impairment were likely to have been caused by systemic vasculitis, leukocyte count was satisfactorily high, and rheumatoid factor was positive on RA test, although it is unclear whether eosinophilia preceded the onset of vasculitis.

On the other hand, the patient was also suspected of PAN as well as AGA, considering the diagnostic criteria of PAN made by the Ministry of Health and Welfare, Japan in 1989 (10). It was not possible, however, to diagnose the patient definitively as PAN before her death, because necrotizing vasculitis was not found in the biopsy specimen of nerve, muscle or kidney. Moreover, anti-nuclear antibodies including anti-RNP antibody and anti-Sm antibody, which are said to be frequently positive in PAN, were not detected in this case. HBs-antigen, which has been suggested to be etiologically related to PAN in some cases, was not positive, either. Therefore, AGA had been thought the most conceivable 
diagnosis until the autopsy.

Histopathologically, both PAN and AGA manifest necrotizing vasculitis with fibrinoid degeneration accompanied by infiltration of inflammatory cells through all the layers of artery $(5,11)$. In PAN, medium- and small-sized muscular arteries are involved, whereas in AGA smaller arteries less $500 \mu \mathrm{m}$ in diameter are affected. Small veins are also involved in AGA, while veins are microscopically saved in PAN. Granulomatous angiitis with multinuclear giant-cells and eosinophilic infiltration in the interstitium may be present in AGA. In 1984, taking the statistics of Japanese cases diagnosed as AGA based on the criteria made by Churg and Strauss, Koizumi reported that granulomatous angiitis was found in 11 of 16 autopsied materials $(68.8 \%)$ and in 9 of 20 biopsied materials (45\%) (12). The distribution of affected organs is very different between PAN and AGA; kidney is one of the most susceptible organs in PAN, while renal involvement is rare in AGA. Lung vessels are frequently involved in AGA, while pulmonary arteries are usually intact in PAN, though bronchial arteritis is occasionally observed (13).

From the histological standpoint therefore, this case appears to have several features characteristic of PAN, because the postmortem examination revealed that necrotizing angiitis was present in medium- to small-sized muscular arteries of several organs including the kidney. Pulmonary arteries were not affected, veins were intact, and granulomatous angiitis was not found in any tissue or organ, though eosinophilic infiltrate was seen in several spaces in spite of corticosteroid therapy for shock. In the kidney, glomeruli were also severely damaged with crescent formation.

Arkin classified arterial lesions found in PAN into four histopathological stages: degenerative stage (stage I), acute inflammatory stage (stage II), granulation stage (stage III) and healed granulation tissue stage (stage IV) (14). This case may correspond to stage II, because the autopsy revealed that acute necrotizing inflammation was present in arterial walls of several organs, and that formation of granulation tissue was not remarkable. However, arteries without a marked change were also found in the identical organs. One of the features of angiitis in PAN is said to be that lesions in various stages are present simultaneously in the same organ (15). The reason that no characteristic lesion was detected in the biopsy specimen may be that the needle failed to catch active lesions distributed focally.

Considering both clinical and histological observations described above, it may be difficult to classify the present case into a single category of either PAN or AGA. Fauci et al proposed a new syndrome that has overlapping features of PAN and AGA (6). In this syndrome, smaller vessels may be involved together with the classic small- and medium-sized muscular artery involvement. Allergic history, peripheral eosinophilia, eosinophilic tissue infiltration, granulomatous reactions, or lung involvement may be present in addition to features characteristic to classical PAN. Later, they further proposed expansion of the spectrum of this syndrome, designating it polyangiitis overlap syndrome, to cover all the forms of overlapping vasculitides, e.g. cutaneous vasculitis and PAN, temporal arteritis and PAN, giant-cell arteritis, AGA and Wegener's granulomatosis, and others (7). The present case seems to correspond to this category; an overlap syndrome of classical PAN and AGA.

Little is known about antigens responsible for the onset of vasculitis, the identification of which the ultimate precise classification of vasculitic syndromes should depend on. At this stage, therefore, it seems to be worthy to report a case like this, because it may contribute to the etiological investigation of vasculitis. In addition, it is important to emphasize that an effort to distinguish one clinical entity from others, e.g. AGA from PAN, should be made, because in typical cases they are significantly different from each other from the therapeutic and prognostic points of view $(9,15)$.

\section{REFERENCES}

1) Kussmaul A, Maier R. Über eine bisher nicht beschriebene eigentümliche Arterienerkrankung (Periarteritis nodosa), die mit Morbus Brightii und rapid fortschreitender allgemeiner Muskellähmung einhergeht. Dtsch Arch Klin Med 1: 484, 1866.

2) Churg J, Strauss L. Allergic granulomatosis, allergic angiitis and periarteritis nodosa. Am J Pathol 27: 277, 1951.

3) Chumbley LC, Harrison EG, DeRemee RA. Allergic granulomatosis and angiitis (Churg-Strauss syndrome). Report and analysis of 30 cases. Mayo Clin Proc 52: 
477, 1977.

4) Lanham JG, Elkon KB, Pusey CD, Hughes GR. Systemic vasculitis with asthma and eosinophilia: A clinical approach to the Churg-Strauss syndrome. Medicine 63: 65, 1983.

5) Lie JT. The classification of vasculitis and a reappraisal of allergic granulomatosis and angiitis (Churg-Strauss syndrome). Mt Sinai J Med 53: 429, 1986.

6) Fauci AS, Haynes BF, Katz P. The spectrum of vasculitis. Clinical, pathologic, immunologic, and therapeutic considerations. Ann Intern Med 89: 660, 1978.

7) Leavitt RY, Fauci AS. Polyangiitis overlap syndrome. Classification and prospective clinical experience. Am J Med 81: 79, 1986.

8) Nagasawa T. Allergic granulomatous angiitis (ChurgStrauss syndrome). Byori to Rinsho 1: 1132, 1983 (in Japanese).

9) Hashimoto H. Clinical management for vasculitis syndrome. Clin Immunol 21 [Suppl 14]: 587, 1989 (in Japanese).
10) Abe T, Takeuchi T. Polyarteritis nodosa. Sogo Rinsho 39: 492, 1990 (in Japanese).

11) Zeek PM. Periarteritis nodosa. A critical review. Am J Clin Pathol 22: 777, 1952.

12) Koizumi F. A clinicopathological study on allergic granulomatosis and angiitis (Churg-Strauss). in: Symposium on the Clinicopathological Studies of Malignant Rheumatoid Arthritis, Allergic Granulomatous Angiitis, Wegener's Granulomatosis and Polyarteritis Nodosa, the Ministry of Health and Welfare, Japan, 1984 (text in Japanese, abstract in English).

13) Koss MN, Antonovych $T$, Hochholzer L. Allergic granulomatosis (Churg-Strauss syndrome). Pulmonary and renal morphologic findings. Am J Surg Pathol 5: $21,1981$.

14) Arkin A. A clinical and pathological study of periarteritis nodosa. Am J Pathol 6: 401, 1930.

15) Fauci AS. Vasculitis. in: Arthritis and Allied Conditions, 10th ed., McCarty DJ, Ed. Lea \& Febiger, Philadelphia, 1985. 